\title{
Repensando a literatura antiga: a inscrição como produção de presença e obra de arte
}

\section{Rethinking the ancient literature: the inscription as production of presence and artwork}

\section{Replanteando la literatura antigua: la inscripción como producción de presencia y obra de arte}

\author{
João Batista Ribeiro Santos*
}

\begin{abstract}
RESUMO
Este estudo tem por objetivo abordar a literatura antiga, por meio das inscrições e reconhecendo as suas funções e suporte, como uma obra de arte. A nossa hipótese é que o lugar comum a que foi transformada a escrita no Ocidente inibiu, desde há muito tempo, a nossa percepção acerca do trabalho artesanal de escrituração. Deslocando do seu estado na indexação arquivística à parte do que se convencionou chamar de arte, inserimos a literatura, a inscrição no quadro dos objetos artísticos, em proveito da arqueologia antropológica.

Palavras-chave: Literatura antiga; cultura material; antigo Oriente-Próximo; obra de arte.
\end{abstract}

\begin{abstract}
This study aims to approach the ancient literature, through the inscriptions and recognizing its functions and support, as a work of art. Our hypothesis is that the commonplace to which Western writing has been transformed has long inhibited our perception of craft-writing work. Moving from its state in archival indexation to the part of what is conventionally called art, we insert literature, the inscription in the framework of artistic objects, for the benefit of anthropological archeology.
\end{abstract}

Keywords: Ancient literature; material culture; ancient Near East; artwork.

\section{RESUMEN}

Este estudio tiene por objetivo abordar la literatura antigua, por medio de las inscripciones y reconociendo sus funciones y soporte, como una obra de arte. Nuestra hipótesis es que el lugar común al que se ha transformado la escritura en Occidente ha inhibido desde hace mucho tiempo nuestra percepción acerca del trabajo artesanal de la escritura. Desplazándose de su estado en la indexación archivística aparte de lo que se convenció llamar arte, insertamos la literatura, la inscripción en el cuadro de los objetos artísticos, en provecho de la arqueología antropológica.

Palabras clave: Literatura antigua; cultura material; antiguo Oriente Próximo; obra de arte.

* Universidade Metodista de São Paulo (Umesp). Docente da Universidade Metodista de São Paulo (UMESP). Mestre em História Política, com especialidade em história antiga e medieval, pela Universidade do Estado do Rio de Janeiro (UERJ), mestre e doutorando em Ciências da Religião pela Universidade Metodista de São Paulo (UMESP). joao.ribeiro@metodista.br . 


\section{Introdução}

Por se tornar comum nos estudos dos processos civilizatórios do Ocidente, principalmente por serem tomadas como fontes as inscrições, códices e livros, a literatura tem sido colocada à parte da cultura material. O letramento, a escrituração, a obra literária (narrativa, discurso, preces, legislação, trato, poema e outros gêneros) em tabuinha de madeira, pedra, cerâmica, metal e outros materiais sequer são lembrados como obras de arte, se não são decorativos ou pictográficos. Com a descoberta de arquivos privados do antigo Oriente-Próximo, ou seja, coleções de documentos preservados por seu valor histórico tratando de mesma pessoa e período, lugar ou motivo, a literatura que era, como documento, uma fonte para a pesquisa da história, passou a merecer atenção por sua presença representativamente artística.

\section{Conceptuação do texto}

Numa apreensão interpretativa dos grandes tratados, a literatura do antigo Oriente-Próximo como tema era abordada no quadro da cultura do que Mario Liverani chamou de "clube dos grandes poderes", ou seja, os grandes reinos de Hattî, Mi-ta-an-ni, A ̌́s-šur-ra-a-a-ú, Ma-a-áš-ri-a$a-n i$ - e Bäb-iliz; atualmente muitas pesquisas têm sido orientadas para os contatos transculturais expressos nas linguagens com algum vestígio entre as populações das

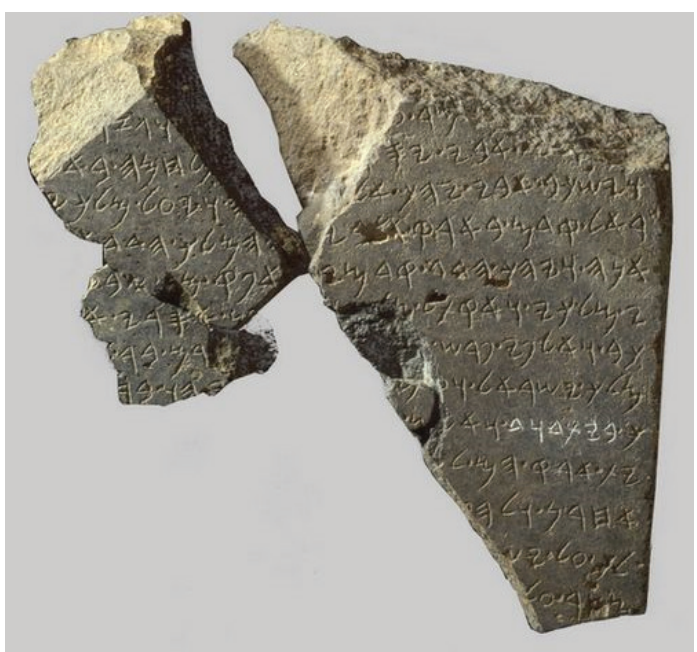

Figura 1: Inscrição do Tēl Dān. Fonte: Center for online Judaic Studies. periferias dos grandes reinos, notadamente no Levante. No repertório de significantes culturais, a imagem ou ícone teoricamente se torna legível fora do seu contexto com o auxílio da inscrição, vice versa, o evento é verificável quando objetificado, ou seja, no objeto que transforma em mnèmé as cenas. A literatura antiga - as inscrições protosinaíticas e os tabletes ugaríticos, como alfabeto, e os signos cuneiformes, como artesania linguística difundida na Idade do Bronze Recente desde os montes Zagros ao norte da África - cumpre esta função mediadora sem deixar de ser um objeto e, por vezes, um pictograma. 
Mais especificamente, estamos situando a literatura no quadro da cultura visual, "as imagens e objetos que implementam formas particulares de ver e, portanto, contribuem para a construção social, intelectual e perceptual da realidade" (PONGRATZ-LEISTEN, 2013, p. 298). Por outras palavras, a evidência textual de um documento de uma grandeza socioétnica não raro é aproximada - ou refletida, encenada - numa iconografia esculpida por outro povo, em outro lugar. No período do império neoassírio, quando, segundo Beate Pongratz-Leisten (2013, p. 306-307), deus e o rei são eternizados em um aspecto de comunicação intensa e a representação visual dessa relação tem por função impulsionar a política e a religião, a inscrição é interpretativa. Por outro lado, do ponto de vista dos antigos israelitas da colônia persa de Yĕhâd, as inscrições estabelecem a comunicação entre Yhwh e o sacerdotado e é o próprio objeto sacro.

Os primeiros códigos de leis são mesopotâmicos e fazem parte da categoria "literatura", mas a inscrição como objeto é uma obra de arte. "Os assiriólogos reservam o termo 'código' às três obras legislativas tripartites (prólogo/corpos de leis/epílogo) atribuídos aos reis Ur-Nammu de Ur (c. 2100), Lipit-Ištar de Išin (c. 1930) e 'Hुmmu-rāpi de Bāb-ilī (c. 1750)" (DÉMARE-LAFONT, 2014, p.310). ${ }^{1}$ No prólogo ressalta-se as qualidades do rei, no corpus a natureza da lei e seu propósito em favor dos súditos e, por fim, as ameaças divinatórias a quem modificar o documento monumental. O código, por seu conteúdo, é literatura política; faz parte, portanto, da agenda ideológica palacial. Com essa intenção, é proclamado pelo rei antes que seja escrito e exposto como monumento público; à diferença de um contrato, o código de leis não raro caracteriza-se por não fazer parte da vida cotidiana de um lugar.

Mas as leis podiam tratar dos mais diversos assuntos, como mulheres, propriedade fundiária, propriedade mobiliária, administração real. Talvez o código mais antigo seja a "Reforma de Urukagina",

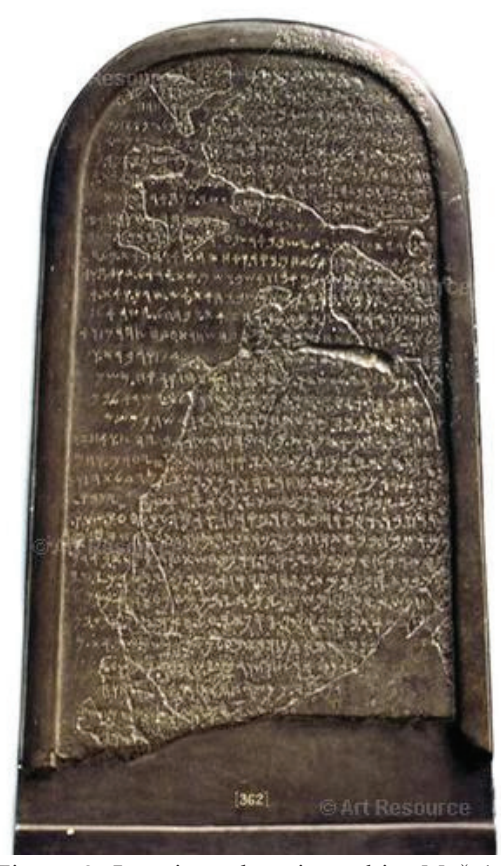

Figura 2: Inscrição do rei moabita Meša‘. Fonte: Art Resource.

\footnotetext{
1 A translação do nome semita dos reis e dos locais foi realizada pelo autor e, portanto, não consta de tal forma no texto citado.
} 
rei de Lagaš, de cerca de 2350 A.E.C. Sophie Démare-Lafont (2014, p. 312) lembra que os biblistas denominam códigos três compilações da Bíblia hebraica, o "Livro da Aliança", a mais antiga camada editorial de leis humanitárias dos israelitas (Êxodo 20,22-23,19), o "Livro da Santidade", mais recente e composto por disposições rituais e sociais para o judaísmo antigo (Levítico 17-27) e o código deuteronomístico, sobretudo consagrado ao direito familial (Deuteronômio 12-26). Mesmo pequenos documentos, como o Código da Aliança, são claramente compósitos; entre prescrições antigas contam-se glosas e ênfases que refletem uma condição posterior ou atualização. No caso de algumas leis, os escribas e artesãos deixam programaticamente lacunas entre narrativas, para intervenções atualizadoras de jurisconsultos locais. Uma das diferenças entre os códigos da Mesopotâmia e os códigos israelitas é que aqueles apresentam formulações casuísticas e os do antigo Yiśräèl têm estilo apodítico.

O caráter legislativo é reconhecido por ser imanente da autoridade pública real, da localidade e, assim, portar a impessoalidade, porquanto distanciar-se do cotidiano. Isso muda consideravelmente em relação aos arquivos privados, tanto quanto os "arquivos mortos" nos quais o seu proprietário anulou ou rejeitou os documentos como os "arquivos vivos", cujos documentos encontrados ainda são relevantes.

Faz-se uma distinção entre os arquivos oficiais que emanam de grandes organizações, palácios e templos, e os arquivos privados, pertencentes a particulares e geralmente exumados em suas casas, como os arquivos de comerciantes assírios no início do segundo milênio exumados em Kaniš, em Ásia Menor, ou os da família babilônica de Murašû, descobertos em Nippur e datados do século IV. Esses arquivos privados nos dizem sobre as realidades sociais e econômicas de seu tempo, às vezes também sobre assuntos domésticos e vida diária. Seus suportes não são os mesmos em todo o Oriente-Próximo (MICHEL, 2014, p. 287). ${ }^{2}$

As inscrições são como que entalhadas em tabletes cuneiformes, na Mesopotâmia, e em ostracon, no Levante; aliás, a origem de grande parte do que sabemos atualmente sobre o desenvolvimento estatal e a produção de azeite, vinho e mel em escala industrial no Yiśrà'ēl Norte, nas regiões de Yizre 'e’l,

2 "Une distinction est effectuée entre les archives officielles émanant des grands organismes, palais et temples, et les archives privées, relevant de simples particuliers et généralement exhumées dans leurs maisons, comme les archives des marchands assyriens du début du $\mathrm{II}^{\mathrm{e}}$ millénaire exhumées à Kaniš, en Asie Mineure, ou celles de la famille babylonienne des Murašû, découvertes à Nippur et datant du $I V^{e}$ siècle. Ces archives privées nous renseignent sur les réalités sociales et économiques de leur époque, parfois aussi sur les affaires domestiques et la vie quotidienne. Leurs supports ne sont pas les mêmes dans tout le Proche-Orient” (MICHEL, 2014, p. 287). 
Tēl Rehōove, principalmente, nos entornos da Sa-me-ri-na-a-a (LEMAIRE, 1977), é resultado do deciframento dos ostraca do século VIII A.E.C. Isto como observação de caso. Nesses documentos estão os modos de ser de parte da população, refletida nos contratos de locação, créditos, débitos, compra e venda, tratos maritais, produção, processos, arbitragem etc. Muitos materiais utilizados como suporte para as inscrições são reutilizados. "Desde o início do segundo milênio, os arquivos privados abundam em cartas. Estas, muito raramente datadas, circulam às vezes protegidas por um envelope de argila no qual aparecem a identidade dos correspondentes e a marca do selo do remetente" (MICHEL, 2014, p. 289). No caso dos arquivos oficiais, há

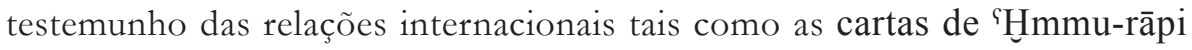
de Bāb-ilī para Šamaš-Hâzir, em Larsa (século XVIII A.E.C.), destaque-se que esse rei é autor do famoso código de leis que leva o seu nome (fig. 3).

A forma de linguagem escrita que deixou como legado os textos mitológicos mais antigos foi a literatura narrativa de expressão suméria. Ela se caracteriza por relatar as proezas da divindade e as epopeias de heróis; mesmo quando se trata de personagens humanos, por suas peculiares capacidades, ela está mais próxima do mundo dos deuses, notadamente em suas encenações guerreiras. Com a queda do império de Ur, no final do terceiro milênio, aparecem cinco poemas cuja inspiração é a ruina de cidades do império - Nippur, Ur, Uruk, Eridu e o santuário real. Por herança, tem origem a literatura akkadiana, cuja obra mais famosa é a epopeia de Gilgameš, fragmentos de um poema paleobabilônio - composições sumérias, mas compostas por poetas akkadianos (BRIQUEL-CHATONNET; LION, 2014, p. 366). Nesse período do segundo milênio, os motivos são as lendas dos reis, as conquistas militares, as expedições de longa duração.

Muitos textos são redigidos em primeira pessoa - um encobrimento da presença do escriba - apresentando-se uma autobiografia de personagens ilustres, muitas compostas após a morte do indivíduo em descrição; ou, essencialmente, como sugerem Françoise Briquel-Chatonnet e Brigitte Lion (2014, p. 370), à maneira de uma escrita biográfica, a exemplo da biografia encomendada pelo rei Nabonide (556-539 A.E.C.) para a sua mãe Adad-Guppi' após a morte dela. Representante do desenvolvimento dessa tradição escribal, a novela assíria influenciou muitas narrativas hebraicas, como as novelas de Šiměšôn e Yôsēpt, as epopeias de Giděôn e Yipětāhh.

Numa síntese acerca da destinação das grandes obras literárias, os donos do poder aparecem como promotores e beneficiários; assim como toda obra que tem origem e função na sociedade, a princípio elas são utilitárias. "Um dos traços mais constantes das monarquias do Oriente-Próximo é ter textos 
gravados destinados a estabelecer a fama do soberano, comemorar suas ações brilhantes e promover a imagem de um bom governante" (VILLARD, 2014, p. 358; cf. também SANTOS, 2013). Os objetos com inscrições desempenham ainda a função mnèmé de um determinado período e reinado, portanto as inscrições são votivas, "pela vida do rei", monumentalizadas em estelas, vasos e em outros objetos de variados formatos (murais, estatuetas gravadas, cones, cilindros, prismas) para exposição pública inclusive nos templos. Por outro gênero, há os anais, registro historiográfico das ações de grandes reis destinado à imortalidade dos eventos triunfais e de fundação; em muitos anais é possível perceber a propaganda como objetivo.

Afixadas por inscrição ou relevo pictográfico, as leis e as reproduções de eventos passam a fazer parte da paisagem nacional; inscrições triunfais e relevos são integrados à decoração dos edifícios públicos. Há, inclusive, reproduções como uma espécie de tradução local de anais de reis akkadianos por escribas de reis elamitas e muitas autojustificações bilíngues. Esses modelos de propaganda real foram seguidos pelos pequenos reis do Levante, basta visualizar a similaridade na estela de $\mathrm{Mes̆a}^{\circ}$ (fig. 2), rei de $M \hat{o}{ }^{\prime} \bar{b}$ - em que o rei narra períodos de conflito entre uma dinastia moabita e reis da dinastia omrida no século IX A.E.C. - e na estela do Tèl Dān (fig. 1), também do

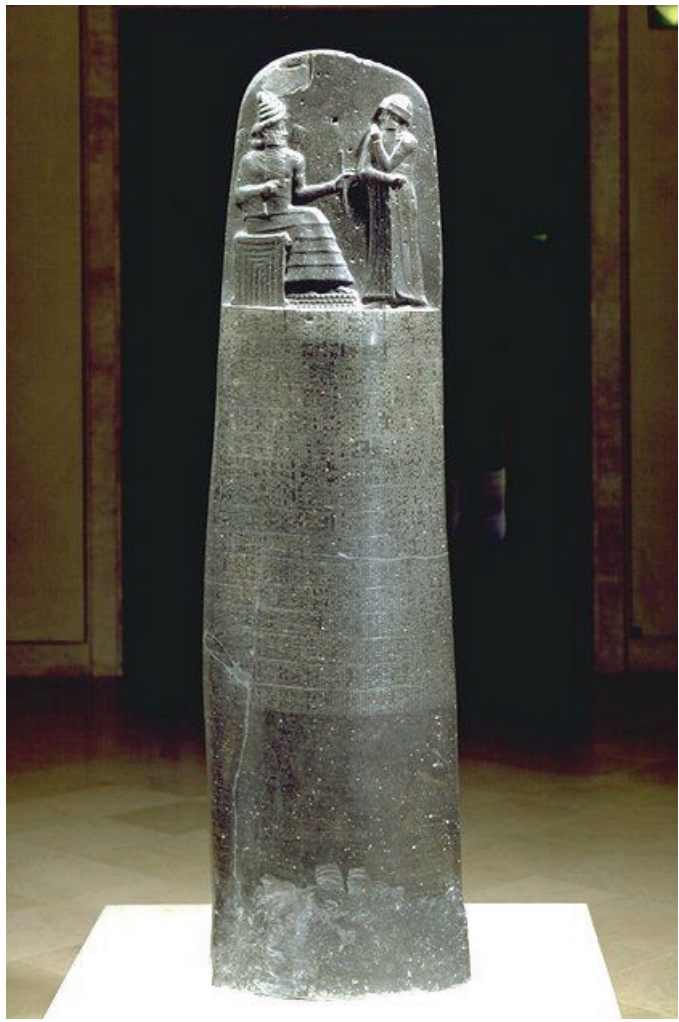

Figura 3: Código de leis do rei babilônio 'Hูmmu-rāpi. Fonte: Art Resource. século IX, e que descreve, entre outros eventos, a guerra do rei Hăazāh'èl, de $\breve{S} a$-imērī̌su, no sul do Levante, à época do assassinato dos reis Yěhôrām de Yiśrā'ēl Norte e 'Ăhazěyāhhu de Yěhûdāh.

As pesquisas arqueológicas têm trazido à luz muitos exemplares de hinos e orações para as divindades, inclusive iconografias e relevos de orantes e 
celebrações cúlticas. Num mundo no qual todos os acontecimentos de uma determinada localidade afetam a totalidade da população e são atribuídos às divindades, as objetificações das relações religiosas testemunham a própria visão de mundo, um mundo que podemos reconhecer como sociedade do ver e do ouvir, antes, portanto, do período helenístico. Do mesmo contexto litúrgico, a literatura sapiencial da época recomenda a oração ao indivíduo como meio de assegurar o bem-estar; escritas, tornaram-se textos utilizados nos cultos e rituais.

De modo geral, Arnaud Sérandour e Pierre Villard (2014, p. 378-379) afirmam que os textos tinham função técnica, serviam de orientação às autoridades religiosas quanto a obter uma resposta das divindades Šamaš e Adad; a leitura dos textos era acompanhada de sacrifício de animais, cujas entranhas eram destinadas às práticas divinatórias. Evidentemente, toda grandeza socioétnica tinha a sua forma de cantar e orar, e inúmeras inscrições revelaram os seus vários gêneros, desde a composição dialética suméria bilíngue até a recitação codificada para os exorcismos akkadianos, os salmos e hinos de Sargon II à deusa Ištar e os salmos e hinos israelitas com paralelismos aliterados de tradição canaanita. Em todos os gêneros constam, à guisa de afecção, os objetos simbólicos da vida pessoal, familial e estatal, além das metáforas psicológicas, sempre em perspectiva.

\section{A história, a literatura}

O debate em torno da presença da literatura na História se dá menos pela qualidade, nessa nossa abordagem, e mais por seus usos na construção política da sociedade. Nesse sentido, a escritura da história em relevo num artefato, a nosso ver, deve ser vestida com uma peça de vestuário fornecida pela literatura, posto que a comunicação emitida pelo historiógrafo recebe fonte linguística técnica e propõe a visualização. Com relação às camadas redatoriais da Bíblia hebraica, Yairah Amit (2006, p. 3) aponta a divergência entre os leitores que veem os textos como "verdade histórica inquestionável" em que avaliam a sua retórica como uma qualidade literária e os leitores que avaliam os dispositivos utilizados pelos escritores como esforços para dar uma impressão de veridicidade aos textos em meio a inconsistências, tratando-os como ficcionais.

Pelo fato de polarizar os grupos de leitores, entendemos que, para ambos os níveis, o anonimato dos escritores e editores não determina o ponto de vista, mas o testemunho arqueológico, a cultura material em concreto. Não apenas as narrações bíblicas, mas muitas inscrições em utensílios e documentos monumentais passaram por várias escriturações e edições, ou tiveram mais de um autor in situ como a estela do Tèl Dān, ou ainda eventos 


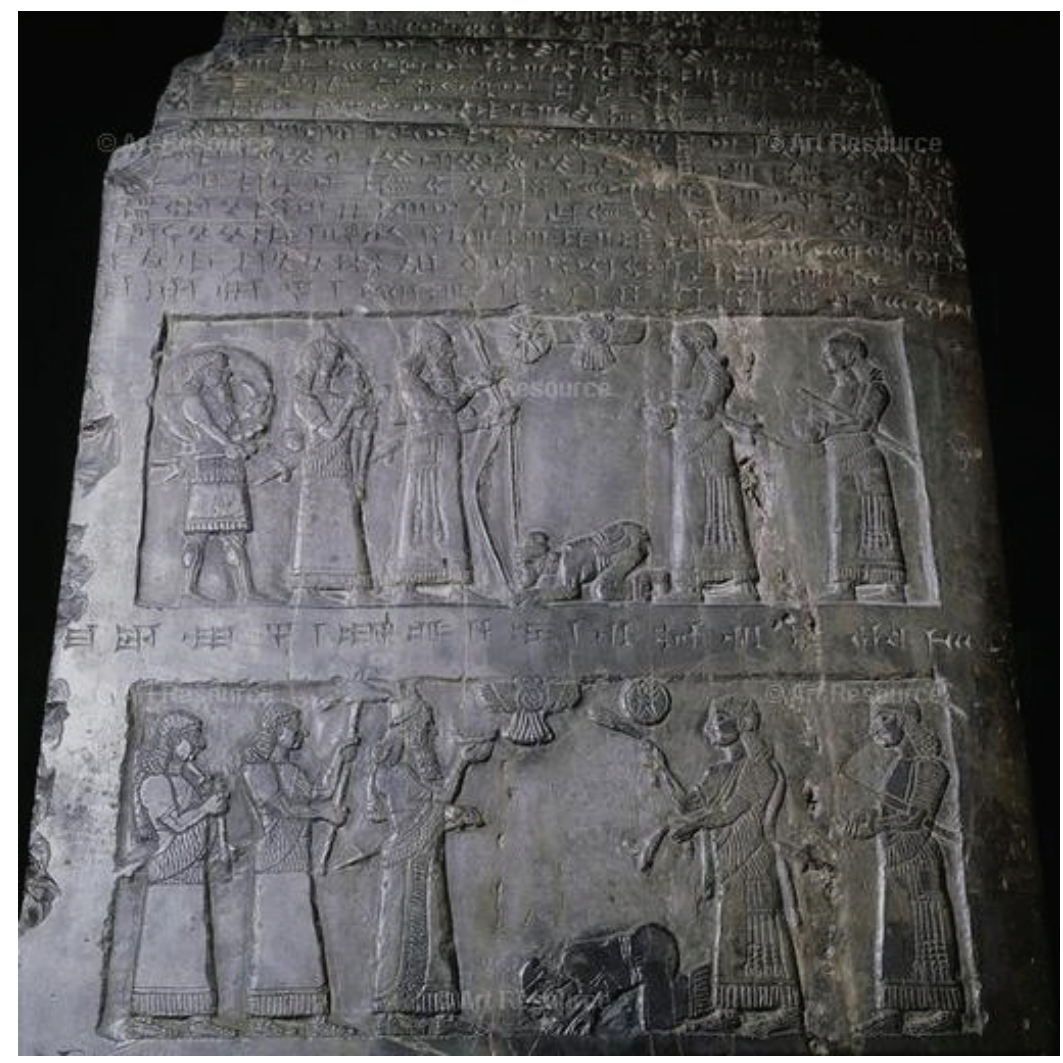

Figura 4: Detalhe do Obelisco Negro do rei assírio Šulmānu-ašaridu. No relevo superior, o rei Sūa de Gilzānu e na parte inferior, o rei golpista Yēhû’ de Yiśrāēèl Norte, ambos em estado submissão. Fonte: Art Resource.

que foram narrados e encenados em pelo menos três artefatos com diferentes perspectivações por escribas de um mesmo rei, como as submissões do rei de Şùr e de Yêhû̉ de Yiśrà'êl Norte ao rei assírio Šulmānu-ašaridu (fig. 4), em cerca de 841 A.E.C. ${ }^{3}$ Destarte, os achamentos e exames arqueológicos podem ser resolutivos, sem, no entanto, encerrar a maioria dos problemas na reconstrução dos acontecimentos passados.

Constatamos que os historiógrafos de eventos do antigo Oriente-Próximo inseriram em sua escrituração da história a narrativa mitológica com tal maestria que é quase inquestionável a coesão das camadas literárias. Como o mito tem a função de ordenar a presença física e política do mundo para as atividades sociais e no antigo Oriente-Próximo propõe explanar a origem de certos eventos tanto naturais quanto sociais (HOLM, 2007, p. 273), à literatura coube o primado da representação dos fatos. As tradições contri-

Sobre isto, cf. YOUNGER, 2016. 
buíram para o aumento dos modos de contação e narração da História, isto ampliou o plano de aplicação do mito que, não sendo restrito à apreensão dos sacerdotes dos cultos, nem cabível apenas às divindades e narrativas de fundação, passou a fazer parte das biografias e autobiografias (SANTOS, 2013; AMIT, 2006), legislações, além das cenas literárias e pictográficas das linguagens e dispositivos comunicacionais. Em adição, ficam ampliadas as nossas evidências a quase tudo que vemos e a algumas formas como estabelecemos os nossos objetos.

\section{Referências bibliográficas}

AMIT, Yairah. Looking at history through literary glasses too. In: AMIT, Yairah; BEN ZVI, Ehud; FINKELSTEIN, Israel; LIPSCHITS, Oded (Eds.). Essays on ancient Israel in its Near Eastern context. A tribute to Nadav Na'aman. Winona Lake, IN: Eisenbrauns, 2006, p. 1-15. BRIQUEL-CHATONNET, Françoise; LION, Brigitte. La littérature narrative. In: BORDREUIL, Pierre; BRIQUEL-CHATONNET, Françoise; MICHEL, Cécile (Dir.). Les débuts de l'Histoire: civilisations et cultures du Proche-Orient ancien. Nouvelle édition revue et augmentée. Paris: Éditions Khéops, 2014, p. 366-372.

DÉMARE-LAFONT, Sophie. Les premiers codes de lois. In: BORDREUIL, Pierre; BRIQUEL-CHATONNET, Françoise; MICHEL, Cécile (Dir.). Les débuts de l'Histoire: civilisations et cultures du Proche-Orient ancien. Nouvelle édition revue et augmentée. Paris: Éditions Khéops, 2014, p. 310-316.

HOLM, Tawny L. Ancient Near Eastern literature: genres and forms. In: SNELL, Daniel C. (Ed.). A companion to the ancient Near East. Malden, MA: Blackwell Publishing, 2007, p. 269-288.

LEMAIRE, André (Introd., trad. et commentaire). Inscriptions hébrä̈ques. Tome 1: Les ostraca. Littératures Anciennes du Proche-Orient. Paris: Éditions du Cerf, 1977.

MICHEL, Cécile. Les archives privées. In: BORDREUIL, Pierre; BRIQUEL-CHATONNET, Françoise; MICHEL, Cécile (Dir.). Les débuts de l'Histoire: civilisations et cultures du Proche-Orient ancien. Nouvelle édition revue et augmentée. Paris: Éditions Khéops, 2014, p. 287-291.

PONGRATZ-LEISTEN, Beate. From pictograph to pictogram: the solarization of kingship in Syro-Anatolia and Assyria. In: ARUZ, Joan; GRAFF, Sarah B.; RAKIC, Yelena (Eds.). Cultures in contact. from Mesopotamia to the Mediterranean in the second millennium B.C. New York; New Haven: The Metropolitan Museum of Art; Yale University Press, 2013, p. 298-309.

SANTOS, João Batista Ribeiro. Pertinências entre os anais egípcios e a biografia antiga: ensaio historiográfico sobre escrita e ideologia nas inscrições cuneiformes e hieroglíficas de eventos oficiais e memoriais do Egito antigo. Em Tempo de Histórias, Brasília, n. 23, p. 7-21, 2013.

SÉRANDOUR, Arnaud; VILLARD, Pierre. Des textes pour les dieux: hymnes et prières. In: BORDREUIL, Pierre; BRIQUEL-CHATONNET, Françoise; MICHEL, Cécile (Dir.). Les débuts de l'Histoire: civilisations et cultures du Proche-Orient ancien. Nouvelle édition revue et augmentée. Paris: Éditions Khéops, 2014, p. 378-386. 
VILLARD, Pierre. Des textes au service du pouvoir. In: BORDREUIL, Pierre; BRIQUEL-CHATONNET, Françoise; MICHEL, Cécile (Dir.). Les débuts de l'Histoire: civilisations et cultures du Proche-Orient ancien. Nouvelle édition revue et augmentée. Paris: Éditions Khéops, 2014, p. 358-365.

YOUNGER, K. Lawson, Jr. A political history of the arameans: from their origins to the end of their polities. Atlanta, GA: SBL Press (Society of Biblical Literature Archaeology and Biblical Studies), 2016.

Submetido em: 27-11-2017

Aceito em: 8-12-2017 